\section{James Valentine}

\section{Formerly Consultant Psychiatrist, University Health Service, Leeds}

James Valentine was born on 2 October 1906, of farming stock, in Glasgow. He won a scholarship to Hutcheson's Grammar School where he was an outstanding student (Dux Medalist, School Captain and Captain of cricket). He read Medicine at Glasgow where, he recalled, he met Ferguson Rodger (later Professor of Psychiatry) in their first week in the Anatomy Room and the two remained close friends until the latter's death. As a student Jim was active in many areas, but is particularly remembered for being a founding member of the National Party of Scotland (now the SNP) and serving on its National Council. He trained at Bethlem Royal Hospital (where, being in London, he was an assiduous theatre-goer). Then he went to Gartnavel Hospital, Glasgow, where his duties included waiting at Central Station to receive consignments of mosquitos from the Mott Clinic, Horton Hospital, Epsom, then used in the treatment of general paralysis of the insane (GPI).

After a travelling scholarship to Johns Hopkins, Baltimore and later a period at the Murray Royal Hospital (combined with consulting at Dundee Child Guidance Clinic) he was appointed to Scalebor Park Hospital, Yorkshire, becoming Physician Superintendent in 1939 on the retirement of Dr Gilmour. Scalebor Park was an unusual mental hospital: it was the last of the five hospitals built by the West Riding County Council, and it was specifically designed for private patients, so it was well appointed and had relatively few

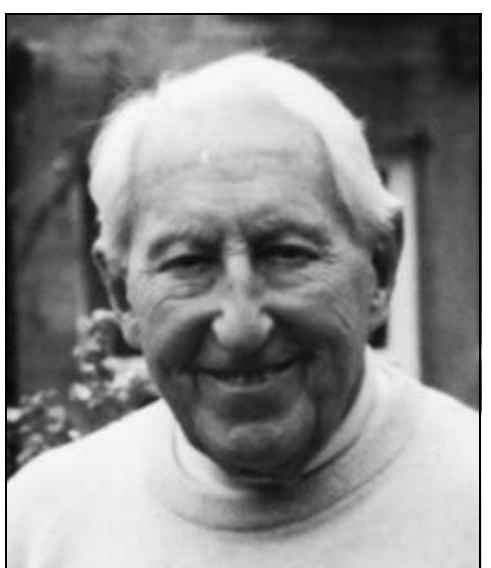

thoroughness, and colleagues were in awe of his extensive hand-written notes. As a teacher, his Friday Case Conferences were well-attended and were an essential feature when the University of Leeds reinstituted its DPM after the War. He was also acting Head of the Leeds Department of Psychiatry until a new professor was appointed

He was a successful administrator and his advice was widely sought. He firmly believed that while home and community treatment should always be the first line of care there would still be a need for small, well-equipped and well-staffed hospitals. Informally, he and Arthur Bowen (of Bootham Park Hospital, York) were the main source of advice to the chronic patients. Much to his chagrin, Jim had to remain in post during the war years. In 1948 he then oversaw the hospital's integration into the National Health Service (NHS) and its development as a comprehensive service for the population of Bradford. (By the time he retired from NHS work in 1971, it was a fully functioning psychiatric hospital with day and rehabilitation units, and specialised facilities for the treatment of alcoholism in adolescents.) He also had an extensive medico-legal practice which he continued after retirement.

Jim was noted first and foremost as an outstanding clinical psychiatrist. He had become interested in psychoanalysis as a schoolboy and he and Ferguson Rodger were particularly stimulated by Freud and Karl Abraham. Influenced by Adolf Meyer, he always sought to understand the origins of a patient's mental phenomena and although he preferred a psychotherapeutic approach he willingly used physical treatments when necessary. Although he could be quite formal in clinical encounters, patients and their relatives appreciated his professionalism and 1948 and he sat on the Regional Advisory Committee from then until 1971. Formally, he was on many committees being the first chairman of the Northern Committee of the National Association for Mental Health (now MIND) and Chairman of the Medical Superintendents' Society (Northern Section) and of the Leeds Psychiatric Association. He had a long association with the British Medical Association, which he joined on graduation, representing the Psychological Medicine Group on the Central Consultants and Specialists Committee for many years.

He married Nina in 1939 and had a long and happy marriage. He was an active sportsman (he had representative trials for hockey in Scotland) and had many cultural interests. He remained active and intellectually alert until shortly before his death on 17 June 2007, aged 100 ! He is survived by two sons (one of whom followed him into medicine) and a daughter.

Timothy Jerram

doi: 10.1192/pb.bp.108.021089 hospital boards which came into being in 